\title{
Use of a Classification Tool to Determine Groups of Women That Contribute to the Cesarean Section Rate: Establishing a Baseline for Clinical Decision Making and Quality Improvement
}

\author{
Valerie Slavin and Jennifer Fenwick
}

OBJECTIVE: To identify the groups of women who are the largest contributors to the cesarean section rate at a maternity facility in South East Queensland, Australia. Examining the characteristics of these women will allow the development of unit-focused initiatives aimed at reducing cesarean sections in these groups of women.

METHOD: A modified version of the Robson Ten Group Classification System was identified as the most appropriate tool to determine cesarean section rates in different groups of women. A prospective clinical audit was then carried out during a 6-month period in 2010 using the tool.

FINDINGS: The Robson Ten Group Classification System identified that planned repeat cesarean section was the largest contributor to the cesarean rate. This was followed by women having their first baby, women having an induction, and women who have a breech presentation at term.

CONCLUSIONS AND IMPLICATIONS: The Robson classification tool was useful in identifying groups of women at risk of a cesarean section. Unit-specific strategies can now be developed and implemented in an effort to lower the rate. These include increasing the vaginal birth after cesarean rate, the uptake of external cephalic version, supporting nonintervention birth environments, and implementing models of care where clinicians are skilled in facilitating normal birth. The value of using such a tool is the ability to monitor change over time as well as facilitating the comparison of data between units of a similar nature.

KEYWORDS: labor; cesarean section; induction of labor; vaginal birth after cesarean; breech; external cephalic version; Robson classification tool; clinical audit

\section{INTRODUCTION}

It is well documented that the cesarean section (CS) rate is now at an all-time high in many resource-rich countries (Belizan, Althabe, \& Cafferata, 2007; National Collaborating Centre for Women's and Children's Health [NCCWCH], 2004; Torloni et al., 2011). Australia is no exception with the proportion of women experiencing CS increasing from $21.8 \%$ in 1999 to $31.5 \%$ in 2009 ( $\mathrm{Li}$, McNally, Hilder, \& Sullivan, 2011). Likewise, in the United
States, the CS rate has increased for the 13th consecutive year to $32.9 \%$ (Martin et al., 2009). This is a rise of more than 50\% since 1996. Throughout Australia, the rate varies by state and territory ranging from $27.6 \%$ to $33.3 \%$, with Queensland and Western Australia recording the highest rate (Li et al., 2011). This is despite recommendations from the World Health Organization (WHO) that the CS rate should be between 5\%-15\% (WHO, United Nations Population Fund, United Nations Children's Fund, \& Averting Maternal Death and Disability, 2009). 
Despite the exponential rise in CS over the past 10-15 years, research from the United Kingdom suggests that the four major clinical determinants of the $\mathrm{CS}$ rate have not changed (NCCWCH, 2004). These remain fetal compromise, "failure to progress" in labor, repeat CS, and breech presentation. The fifth most common reason given for performing a CS is now reported as "maternal request" (NCCWCH, 2004). Although Australian data is available, accurate comparisons are difficult because of the different collection tools used across states and territories. However, what data is available nationally indicates that repeat CS is the leading cause contributing to between $32.7 \%$ and $37 \%$ of the overall CS rate. The second largest group of contributors to the CS rate includes failure to progress, cephalopelvic disproportion, psychosocial reasons, and woman's choice. These are followed by fetal distress and malpresentation (Li et al., 2011).

Evidence suggests that variation in clinical practice contributes to variation in CS rate $(\mathrm{NCCWCH}$, 2004). For example, the use of continuous electronic fetal monitoring in labor is associated with the increases in CS rates but not with the reduction in perinatal mortality rate (Alfirevic, Devane, \& Gyte, 2006). A clinical unit's CS rate can also be affected by organizational factors such as designated level of care (i.e., tertiary referral center) or the presence of a neonatal intensive care unit (Robson, 2001).

Most obstetric units can usually report their CS rate, and there is little doubt that clinical audit and feedback are important tools in ensuring quality service provision (Costa, 2010). Robson (2001) argues that this information, in isolation, is often of limited value because units may differ significantly in terms of the clients they care for and/or the services they provide. The ability to systematically collect additional data, which provides information regarding the determinants of CS within and across units, is considered by Robson to be more helpful. With this in mind, Robson (2001) developed what is referred to as the Ten Group Classification System (TGCS; Howell, Khor \& Johnston, 2008; Torloni et al., 2011). This method of classification aims to prospectively identify clinically relevant groups of women in which the rate of CS is determined and could be subsequently compared over time in one unit and/or between units. The tool thus provides a way of evaluating changes in practice to improve perinatal care.

Such as many other maternity facilities around Australia, one unit in South East Queensland is struggling with a high CS rate. Although a $29 \%$ CS rate is lower than the national average, this rate is of concern
(Slavin \& Roberts, 2010, unpublished). Although the maternity unit records annual statistics regarding CS rates, there is no other beneficial data available to inform practice change initiatives. The unit does not have any electronic database, and at the time of the study, only minimal birth details were recorded in a handwritten paper-based birth register.

\section{AIM}

The aim of this study was to identify the groups of women who are the largest contributors to the CS rate at one maternity facility in South East Queensland, Australia. Through the process of classification, it was hoped that valuable evidence would be gained on the most likely strategies for reducing the CS rate. In addition, we hoped to highlight the beneficial aspects of collecting data that could subsequently be compared and shared using such a classification tool.

\section{METHOD}

A prospective audit was carried out for all women that birthed at the unit during a 6-month period from June 1, 2010 to November 30, 2010.

\section{SETTING}

The maternity unit has approximately 3,000 births per year and currently provides low, medium, and selected high-risk care. Models of care include consultant-led care, shared care with general practitioners, and midwife-led care for women deemed at low risk for complication. A continuity of midwifery care model, in the form of a Midwifery Group Practice, is also available to a small number of women every year.

\section{DATA COLLECTION TOOL}

Data was collected using a hybrid version of the Robson TGCS. The decision to use this tool was based on the findings of a systematic review undertaken by Torloni and associates (2011). The authors of the review concluded that the Robson tool was conceptually easy and simple to use, facilitating the identification and comparison of CS rates in 10 different groups of women. Torloni et al. 
(2011) also made the point that the tool was appropriate cross-culturally. The groups are numbered from 1 to 10 and are based on a combination of characteristics such as gestation, parity, fetal presentation, type of labor, mode of birth, and past history of a CS.

In their review, Torloni et al. (2011) also acknowledged that although the original TGCS showed where differences lay, it did not on its own explain the reasons for the differences. As a result, the authors suggested that a hybrid model with additional classification layers might be more appropriate. Based on these recommendations, the TGCS was adapted to allow additional data collection to further inform practice. These additions included such things as recording whether the woman had labor induced, had an unplanned CS before labor commenced, or had an elective CS. All 10 groups (with adaptions) are described in Table 1.

\section{DATA COLLECTION}

During the audit period, a Robson score (see Table 1) was allocated to all women who gave birth at the study site. Regular in-service education sessions were held before the commencement of the study to ensure that all the midwives working in the birth unit were aware of how to correctly allocate a score when completing the paper-based birth register. Some of the information required to allocate a score was already documented in the birth register. However, additional data such as gestation were required. With the consent of the birth unit manager, the birth register was adapted and columns added requesting this information. A column was also allocated for the Robson score. To ensure correct allocation, the researchers rechecked all allocations and crossreferenced each birth using various other paper-based resources such as the admission, induction, and elective CS books (all of which provided various additional information such as reason for admission, induction, or cesarean). From the birth register, nonidentifiable data in the form of Robson score and mode of birth was then collected for each woman.

\section{EXCLUSIONS}

Group 10 of the Robson classification tool accounts for all women giving birth at 36 weeks or less. The study site presently transfers all women with a potential preterm birth between 24 weeks and 32 weeks gestation to tertiary hospitals. Women less than 24 weeks remaining at the maternity unit were excluded from the study, given that this gestation dictates management.

\section{DATA ANALYSIS}

Data was entered into an Access database. Simple descriptive statistics, in the form of frequencies and percentages,

\section{TABLE 1 Robson Ten Group Classification Tool (with Adaptions)}

$\begin{array}{lllll} & & & & \text { SINGLETON/MULTIPLE } \\ \text { PARITY } & \text { GESTATION } & \text { PRESENTATION } & \text { PREGNANCY } & \text { ONSET } \\ \text { Primip } & \geq 37 & \text { Cephalic } & 1 & \text { Spontaneous } \\ \text { Primip } & \geq 37 & \text { Cephalic } & 1 & \text { IOL } \\ \text { Primip } & \geq 37 & \text { Cephalic } & \text { CS before labor } & 2 \mathrm{~b} \\ \text { Multip (Exc previous CS) } & \geq 37 & \text { Cephalic } & 1 & \text { Spontaneous } \\ \text { Multip (Exc previous CS) } & \geq 37 & \text { Cephalic } & 1 & 3 \\ \text { Multip (Exc previous CS) } & \geq 37 & \text { Cephalic } & 1 & \text { IOL } \\ \text { Multip (Previous CS) } & \geq 37 & \text { Cephalic } & 1 & \text { Elective CS } \\ \text { Multip (Previous CS) } & \geq 37 & \text { Cephalic } & 1 & \text { IOL } \\ \text { Multip (Previous CS) } & \geq 37 & \text { Cephalic } & 1 & \text { Elective CS } \\ \text { Primip } & \text { Any } & \text { Breech } & 1 & \text { Spontaneous } \\ \text { Multip (including previous CS) } & \text { Any } & \text { Breech } & 1 & \text { Any } \\ \text { Any (including previous CS) } & \text { Any } & \text { Any } & 1 & \text { Any } \\ \text { Any (including previous CS) } & \text { Any } & \text { Any } & >1 & \text { Spontaneous } \\ \text { Any (including previous CS) } & \text { Any } & \text { Any } & >1 & \text { IOL } \\ \text { Any (including previous CS) } & \text { Any } & \text { Not cephalic or breech } & \text { Any } \\ \text { Any (including previous CS) } & 36 \text { or less } & \text { Cephalic } & 1 & \text { Elective CS }\end{array}$

Note Primip $=$ primipara $\mathrm{IOL}=$ induction of labor; $\mathrm{CS}=$ cesarean section; Multip = multipara. Adapted from Robson, M. Classification of Caesarean sections. Fetal and Maternal Medicine Review. 2001; 12(1): 23-39. Copyright by Cambridge University Press. Reprinted with permission. 
TABLE 2 Robson Classification for Women Birthing at Gold Coast Hospital

\begin{tabular}{|c|c|c|c|c|c|}
\hline $\begin{array}{l}\text { ROBSON } \\
\text { SCORE }\end{array}$ & $\begin{array}{l}\text { SIZE OF GROUP } \\
N=1,701(100 \%)\end{array}$ & $\begin{array}{l}\text { ELECTIVE CS } \\
N=203(11.9 \%)\end{array}$ & $\begin{array}{l}\text { EMERGENCY CS } \\
N=260(15.3 \%)\end{array}$ & $\begin{array}{l}\text { TOTAL CS } \\
N=463(27.2 \%)\end{array}$ & $\begin{array}{l}\text { OVERALL } \\
\text { CONTRIBUTOR } \\
\text { TO CS RATE (\%) }\end{array}$ \\
\hline 1 & $496(29.2)$ & $0(0.0)$ & $81(16.3)$ & $81(16.3)$ & 4.8 \\
\hline 2 & 231 (13.6) & $9(3.9)$ & $62(26.8)$ & $71(30.7)$ & 4.2 \\
\hline 3 & $449(26.4)$ & $0(0.0)$ & $20(4.5)$ & $20(4.5)$ & 1.2 \\
\hline 4 & $179(10.5)$ & $27(15.1)$ & $15(8.4)$ & $42(23.5)$ & 2.5 \\
\hline 5 & 197 (11.6) & $133(67.5)$ & $28(14.2)$ & $161(81.7)$ & 9.5 \\
\hline 6 & $21(1.2)$ & $11(52.4)$ & $9(42.8)$ & $20(95.2)$ & 1.2 \\
\hline 7 & 27 (1.6) & $15(55.6)$ & $12(44.4)$ & 27 (100) & 1.6 \\
\hline 8 & $22(1.3)$ & $5(22.7)$ & 9 (40.9) & $14(63.6)$ & 0.8 \\
\hline 9 & $1(0.1)$ & $0(0.0)$ & 1 (100) & $1(100)$ & 0.1 \\
\hline 10 & $78(4.6)$ & $3(3.8)$ & $23(29.5)$ & $26(33.3)$ & 1.5 \\
\hline
\end{tabular}

Note. CS $=$ cesarean section.

were used to describe the study group. The results were initially analyzed as a whole as suggested by Robson (2001) (see Table 2). They were then analyzed in greater detail using the adapted classification (see Table 3).

\section{ETHICAL CONSIDERATIONS}

Ethical approval was not required for this clinical audit as no client identification was required. A letter from the chair of ethics committee was received, supporting the study and any publication of results.

\section{RESULTS}

During the 6-month audit period, 1,701 births took place at the maternity unit. Of these, $463(27.2 \%)$ were by CS-203 (11.9\%) were classified as elective CS, and 260 (15.3\%) were emergency/nonelective CS. The number of women classified to each Robson group is provided as follows. Table 2 provides a summary of this information.

Group 1: Nulliparous women with single cephalic pregnancy, $\geq 37$ weeks gestation in spontaneous labor

TABLE 3 Additional Data Collected

\begin{tabular}{|c|c|c|c|c|}
\hline & $\begin{array}{c}\text { VAGINAL BIRTH } \\
n \%\end{array}$ & $\begin{array}{c}\text { ELECTIVE CS } \\
n \%\end{array}$ & $\begin{array}{c}\text { EMERGENCY CS } \\
n \%\end{array}$ & $\begin{array}{c}\text { TOTAL IN GROUP } \\
n \%\end{array}$ \\
\hline Group 2 & $160(69.3)$ & $9(3.9)$ & $62(26.8)$ & $231(100)$ \\
\hline 2a IOL & $160(69.3)$ & $0(0.0)$ & $60(25.9)$ & $220(95.2)$ \\
\hline 2b CS before labor & $0(0.0)$ & $9(3.9)$ & $2(0.9)$ & $11(4.8)$ \\
\hline Group 4 & $137(76.5)$ & $27(15.1)$ & $15(8.4)$ & $179(100)$ \\
\hline 4a IOL & $137(76.5)$ & $0(0.0)$ & $11(6.1)$ & $148(82.7)$ \\
\hline 4b CS before labor & $0(0.0)$ & $27(15.1)$ & $4(2.2)$ & $31(17.3)$ \\
\hline Group 5 & $36(18.3)$ & $133(67.5)$ & $28(14.2)$ & $197(100)$ \\
\hline 5 a IOL & $7(3.6)$ & $0(0.0)$ & $2(1.0)$ & $9(4.6)$ \\
\hline 5b Elective CS & $0(0.0)$ & $133(67.5)$ & $0(0.0)$ & $133(67.5)$ \\
\hline 5c Spontaneous labor & $29(14.7)$ & $0(0.0)$ & $26(13.2)$ & 55 (27.9) \\
\hline Group 8 & $8(36.4)$ & $5(22.7)$ & $9(40.9)$ & $22(100)$ \\
\hline 8a IOL & $1(4.5)$ & $0(0.0)$ & $2(9.1)$ & $3(13.6)$ \\
\hline 8b Spontaneous labor & $7(31.8)$ & $0(0.0)$ & $7(31.8)$ & $14(63.6)$ \\
\hline 8c Elective CS & $0(0.0)$ & $5(22.7)$ & $0(0.0)$ & $5(22.7)$ \\
\hline
\end{tabular}

Note. $\mathrm{CS}=$ cesarian section; $\mathrm{IOL}=$ induction of labor. 
There were 496 women (29.2\% of all births) classified into Group 1, making it the largest group. Eighty-one women (16.3\%) were recorded as having an emergency CS. The reasons for the cesareans were not analyzed within this group.

Group 2: Nulliparous women with single cephalic pregnancy, $\geq 37$ weeks gestation who either had labor induced or were delivered by CS before labor commenced

Group 2 categorizes pregnant women who, for whatever reason, required delivery with the pregnancy being brought to an end. Robson (2001) argued that it is important to initially consider these women as one group given that although one medical practitioner/obstetrician may be prepared to induce a labor, another may deliver by CS without induction. In this study, there were 231 women (13.6\%) assigned to Group 2. Of these, $71(30.7 \%)$ resulted in CS with nine women $(3.9 \%)$ having an elective CS, and 62 women (26.8\%) having an emergency CS.

Additional data in the form of induction of labor (IOL) and CS before labor were also recorded for this group of women (see Table 3). Of the 231 women in this group, 220 (95.2\%) had an IOL. Some 60 women (25.9\%) progressed to have an emergency CS. This compares with only $16.3 \%$ in Group 1 who had a spontaneous labor. Eleven women $(4.8 \%)$ had their pregnancy ended before labor commenced by CS. Two women $(0.9 \%)$ were recorded as having an emergency $\mathrm{CS}$ and nine (3.9\%) as having an elective CS.

Group 3: Multiparous women without a previous uterine scar, with single, cephalic pregnancy, $\geq 37$ weeks gestation in spontaneous labor

Four hundred and forty-nine women (26.4\%) were classified to Group 3, which represented the second largest group of birthing women. No women in this group had an elective cesarean. Twenty women (4.5\%), however, experienced an emergency CS.

\section{Group 4: Multiparouswomen without a previous uterine} scar, with single cephalic pregnancy, $\geq 37$ weeks gestation who either had labor induced or were delivered by CS before labor commenced

Group 4, like Group 2, captures the number of women having their pregnancy ended by induction or a CS before labor commenced. One hundred and seventy-nine women (10.5\%) were assigned to this category. Whereas 137 (76.5\%) gave birth vaginally, 42 women $(23.5 \%)$ had a CS. Fifteen women (8.4\%) birthed by emergency CS, with a surprising 27 women (15.1\%) who had previously had a vaginal birth having an elective cesarean.

Using the additional data collected, it was identified that $148(82.7 \%)$ women had an IOL. Of these, 11 (6.1\%) experienced emergency CS (See Table 3).

Group 5: All multiparous women with at least one previous uterine scar, with single cephalic pregnancy, $\geq 37$ weeks gestation

Group 5 was the third largest group-197 women (11.6\%). However, it accounted for the largest number of CS with 133 women (67.5\%) recorded as having an elective cesarean. Some 28 (14.2\%) experienced an emergency cesarean.

To provide additional insight into this group of women, further information was recorded on, IOL, women who had a spontaneous labor and women who had an elective CS (Table 3). Nine women (4.6\%) had an IOL, with seven (3.6\%) giving birth vaginally, and two women (1.0\%) progressing to an emergency CS. Fifty-five women (27.9\%) went into spontaneous labor. Of these women, 29 (52.7\%) had a vaginal birth after cesarean (VBAC), and 26 (47.3\%) had an emergency CS.

Classification of women having an emergency CS in this group, however, is somewhat problematic. At the study site, women who have been booked for a repeat CS but arrive in spontaneous labor or with ruptured membranes and progress to a CS would be recorded as having an emergency CS. Anecdotal evidence would suggest that most women having an emergency CS in Group 5 were already booked for a repeat planned CS. The number of women who actually experienced problems in labor is unknown.

\section{Group 6: All nulliparous women with a single breech presentation}

Group 6 consists of all nulliparous women with a breech presentation irrespective of gestation. Robson (2001) argues it is necessary to capture this group, as it is the breech presentation that affects the management decisions. Of the 21 women allocated to Group 6, 20 had a CS-eleven (52.4\%) were recorded as elective and nine $(42.8 \%)$ as emergencies. 
Group 7: All multiparous women with a single breech pregnancy including women with previous uterine scars

Twenty-seven women (1.6\%) were allocated to this group all of whom had a CS.

Group 8: All women with multiple pregnancies including women with uterine scars

Twenty-two women (1.3\%) had a multiple pregnancy during the study period and were allocated to Group 8. Eight women (36.4\%) had a vaginal birth with the remaining 14 women $(63.6 \%)$ having a CS-five (22.7\%) elective and nine (40.9\%) emergency.

The collection of additional data in the group revealed that of the 14 women who experienced spontaneous labor, half had an emergency CS (see Table 3). Of the three women who had an IOL, one birthed vaginally. One woman actually experienced a vaginal birth for twin 1 but an emergency CS for twin 2. The vaginal birth in this case was not taken into account because the emergency CS was most relevant for the Robson classification.

\section{Group 9: All women with a single pregnancy with a transverse or oblique lie including women with previous uterine scar}

This was the smallest group with only one woman allocated to Group 9. She experienced an emergency cesarean.

Group 10: All women with a single, cephalic pregnancy, $\leq 36$ weeks gestation including women with previous uterine scars

Seventy-eight women (4.6\%) were 36 weeks or less at the time of birth. Two thirds gave birth vaginally $(n=52)$, with the CS recorded as $33.3 \%$. Three women $(3.8 \%)$ had an elective CS, and 23 (29.5\%) were recorded as having an emergency CS.

\section{Overall Rates and Contribution of Each Group to the Cesarean Section Rate}

The highest rates of CS were in women with breech presentations (Groups 6 and 7, 95.2\% \& 100\%, respectively). This was followed by women with a history of a previous CS (Group 5, 81.7\%) and women with a multiple pregnancy (Group 8, 63.6\%).

The highest group contributing to the overall CS rates was, however, women with a previous CS (Group 5,
9.5\%). This was followed by women having their first baby (Group 1, 4.8\%; and Group 2, 4.2\%). Group 4 multiparous women who had their pregnancy brought to an end (via IOL or CS before labor) were the next largest contributor to the overall CS rate $(2.5 \%)$. Of the 42 women in this group who experienced a CS, $64 \%$ were classified as elective, despite having had a previous vaginal birth. The rates of CS and contribution of each group to the overall CS rate are summarized in Tables 2 and 3 .

\section{DISCUSSION}

This small project used a modified version of the Robson classification tool (2001) to highlight the groups of women who experience the most CS within the study setting. The results provide some baseline data from which further analysis can be undertaken with the anticipation of developing initiatives to reduce the CS rate in the largest groups-repeat CS, breech presentation, and women giving birth to their first baby entering labor either spontaneously or through IOL. The value of using the TGCS is the ability to monitor the effectiveness of implemented strategies as well as to compare units.

\section{Repeat Cesarean Section Versus Vaginal Birth After Cesarean}

Pregnant women with a history of a previous CS (Group 5) contributed most to the overall CS rate. The rate of CS in this group of women at the study site is comparable to that of the national average of $83.6 \%$ (Li et al., 2011). Strategies to decrease the CS rate in this group are likely to make a significant difference to overall rates. One initiative must be to increase the number of women planning and successfully giving birth vaginally after a previous CS.

More than 20 years ago, the WHO (1985) stated that there was no evidence that a repeat CS is required after a previous transverse lower segment CS birth. Despite the low rates, VBAC is supported for most women (National Institute for Health and Clinical Excellence [NICE], 2011; Royal College of Obstetricians and Gynaecologists [RCOG], 2007; Statewide Maternity and Neonatal Clinical Guidelines Program, 2009). A significant body of evidence demonstrates that between $70 \%$ and $80 \%$ of women who have had a previous lower segment CS should be able to give birth vaginally in their subsequent pregnancy (Cahill, Tuuli, Odibo, Stamilio, \& Macones, 2010; Dodd, Crowther, Huertas, Guise, 
\& Horey, 2004; Tahseen \& Griffith, 2010). For those women who have experienced a vaginal birth prior to their CS, the success rate is as high as $87 \%-90 \%$ (RCOG, 2007). There is growing evidence that when women have midwives as their primary carer, the rates of success are higher. For example, the VBAC success rate for women attending a birth center and pursuing a VBAC has been noted to be between $87 \%$ and $98 \%$ (Albers, 2005; Harrington, Miller, McClain, \& Paul, 1997). This suggests that VBAC is achievable in environments other than those dominated by the medical model and where midwives are the primary carers.

In terms of maternal and neonatal outcome, a recent review of 79 studies comparing repeat planned CS to vaginal birth, identified that CS may have substantially greater risks compared with vaginal birth (Belizan et al., 2007). Successful VBAC has the lowest maternal and neonatal morbidity when compared to CS, is associated with improved maternal emotional health outcomes, and is the most cost-effective birthing option (Belizan et al., 2007; Cahill et al., 2006; Flamm et al., 1988; Stamilio \& Shanks, 2008).

Although the focus on the "risk" of uterine rupture occurring in a woman attempting a vaginal birth has driven clinical practice and decision making over the last 10 years, the absolute risk of adverse outcomes occurring remains statistically small (less than 1\%) (Flamm, Goings, Liu, \& Wolde-Tsadik, 1994; Landon et al., 2004; Macones et al., 2005; McMahon, Luther, Bowes, \& Olshan, 1996; Miller, Diaz, \& Paul, 1994; Shipp et al., 1999). Rozen, Ugoni, and Sheehan (2011) suggest that the maternal and neonatal morbidity associated with VBAC is comparable to primiparous women undergoing a vaginal birth. Most women with one previous low transverse CS are candidates for VBAC. Macones et al. (2005) agree, further suggesting that women who have also experienced a previous vaginal birth should be encouraged to have a VBAC. In fact, there is also growing evidence to support vaginal birth following more than one cesarean (American College of Obstetricians and Gynecologists [ACOG], 2010; Tahseen \& Griffith, 2010). VBAC should therefore be encouraged for most of these women.

In addition, consideration should be given to the large number of pregnant women booked for a repeat CS who are regularly admitted in spontaneous labor or with ruptured membranes. In most instances, these women progress to CS despite having a good chance of achieving a successful VBAC. Landon et al. (2004) suggest that given this scenario, best practice would dictate discussion with the woman and the development of a plan of care should labor commence prior to the scheduled CS.

To this end, maternity hospitals need to reexamine how best to provide care in a subsequent pregnancy. Policies and procedures for women having a VBAC should reflect the best available evidence and move away from inflexible, restrictive, and detrimental practices (Fenwick, Gamble, \& Mawson, 2003). Women with a history of a CS should be able to access noninterventionist environments such as birth centers and midwifery continuity of care models. In addition, as Fenwick and associates (2003) stated nearly 10 years ago, health care professionals "need to explore their own practice philosophies and become far more skilled in facilitating a noninterventionist approach to childbirth within an environment that promotes birth as normal" (p. 16).

\section{Supporting Normal Birth}

Currently, the Australian CS rate for primiparous women is 32.8\%, with Queensland reporting the second highest rate of $34 \%$, coming second to Western Australia (34.8\%) (Li et al., 2011). Keeping birth normal, especially in the first pregnancy, is becoming increasingly recognized as an important strategy in tackling the high CS rates (New South Wales Department of Health, 2010; Royal College of Midwives, RCOG, \& National Childbirth Trust, 2007). Women having their first baby (Groups 1 \& 2) were the second and third largest contributors to the overall CS. Although first time mothers experiencing spontaneous labor had one of the lowest proportions of CS, the large size of the group still accounted for a high number of CS. Although the reasons for these cesareans were not analyzed in this study, anecdotal evidence would suggest that "failure to progress" was one of the main contributing factors leading to CS, which is consistent with the evidence (Li et al., 2011).

The results also revealed that there were 27 women (Group 4) who had an elective CS after previously giving birth vaginally; this represents $15.1 \%$. Although there will always be contraindications to vaginal birth, such as placenta previa, the high rate is of concern. This group of women and the reasons for the elective CS need further investigation in the hope that women who do not have any medical complications that prohibit vaginal birth might achieve a safe and satisfying vaginal birth within the context of a positive birth experience. Recent guidance provided by NICE (2011) suggests that women who are anxious and/or fearful of childbirth should be provided with an opportunity to talk through the issues 
with a supportive health care professional. Referral to a care provider with perinatal mental health expertise may also be appropriate (NICE, 2011, p. 6). Only after such support should elective cesarean be booked if vaginal birth is still not seen as an acceptable option.

\section{The Importance of Reducing the Induction of Labor Rate}

Women having their first baby who experienced an IOL are of particular interest. The results of this study clearly show that the rates of CS were significantly higher in this group of women as opposed to those that went into spontaneous labor. Similarly, there was a doubling of the emergency CS rate in multiparous women being induced. The findings of this study support the growing evidence that IOL is associated with higher CS rates (Brennan, Murphy, Robson, \& O’Herlihy, 2011). Interventions or practice changes to reduce the IOL rate are important strategies in lowering the overall CS rates. The most obvious place to start is to review practices and policies around routine IOL during (or sometime before) the 41 st week of pregnancy.

The current consensus of the need for IOL before 42 completed weeks was largely a result of the work of Hannah and associates (1992). The Canadian researchers randomized women experiencing a prolonged pregnancy to either IOL or serial fetal monitoring while awaiting the onset of labor. The results of the trial demonstrated a lower CS rate for fetal distress in the IOL group (5.7\% vs. $8.3 \%, p=0.003)$. The authors thus recommended IOL at 41 completed weeks of pregnancy. Since this trial, two systematic reviews have been conducted (Caughey et al., 2009; Gülmezoglu, Crowther, \& Middleton, 2006). The authors of both reviews continue to claim that IOL is not associated with CS and that it reduces fetal morbidity. However, significant methodological critique of all these pieces of work has since taken place, calling into question the appropriateness of routine use of induction for well pregnant women and their fetuses before 42 weeks of pregnancy (King, Pilliod, \& Little, 2010; Mozurkewich, Chilimigras, Koepke, Keeton, \& King, 2009). Clinical care needs to focus on developing management strategies that are based on the woman's own individual needs, desires, and preferences. This may incorporate strategies such as sweeping of the membranes (Boulvain, Stan, \& Irion, 2005; Siozos \& Stanley, 2005) and complementary methods of induction such as acupuncture, breast simulation, and shiatsu (Ingram, Domagala, \& Yates, 2005; Kelly, Kavanaugh, \& Thomas,
2005; Smith \& Crowther, 2004). In addition, researchers need to continue to investigate the effectiveness of noninvasive ways of cervical ripening and/or IOL.

\section{Promoting External Cephalic Version}

The management of the care of women with a breech presentation at term remains an important clinical issue for debate, discussion, and investigation. In this study $95 \%-100 \%$ of women with a breech presentation had a CS. This high rate reflects current practice and a diminishing skill base around the care and management of vaginal breech birth. Although vaginal breech birth remains a contested issue because of the initial results of the Term Breech Trial (Hannah et al., 2000), subsequent methodological critique and more recently the longterm follow-up studies show no difference in outcomes (Fahy, 2011; Glezerman, 2006; Kotaska, 2004). An Australian retrospective population-based study identified a dramatic decline in vaginal breech births following the Term Breech Trial from $23.1 \%$ in 1991 to $3.7 \%$ in 2005 (Sullivan, Moran, \& Chapman, 2009). Other international studies identify the same significant decline (Daviss, Johnson, \& Lalonde, 2010; Hehir et al., 2011).

One well-researched and important clinical procedure that has the potential to reduce the CS rate in this population is external cephalic version (ECV) (Hutton \& Hofmeyr, 2006). ECV has been shown to be both safe and cost effective (Fok et al., 2006; Grootscholten, Kok, Oei, Mol, \& Van der Post, 2008; NICE, 2011; Tan, Macario, Carvalho, Druzin, \& El-Sayed, 2010). The success of the procedure ranges from $30 \%$ to $84 \%$ and is dependent on parity of the pregnant woman and the degree of skill of the operator (Burgos et al., 2011; NICE, 2011).

At the time of the study, the maternity unit did not have an effective and well-organized ECV service. Although the number of CS for breech presentation was relatively small, the women in these groups would nonetheless benefit from an effective ECV service. ECV is also an important strategy to avoid a primary CS, which significantly impacts on a woman's future reproductive outcomes.

\section{CONCLUSION}

The most recent national data identifies that 92,687 CS were performed across Australia, accounting for 31.5\% of women who gave birth in 2009 (Li et al., 2011). Each cesarean represents its own risks to both mother and 
newborn. The results of this study demonstrate that certain groups of women are more at risk for a CS than others. These included women who have had a previous CS, women having their first baby who enter labor both spontaneously or through induction, and women with a breech presentation. Strategies can now be developed and implemented in an effort to lower the CS rate within these groups. Such strategies include increasing the VBAC rate, the uptake of ECV, and supporting nonintervention birth environments and models of care where clinicians are skilled in facilitating normal birth. Although the results are limited to the study site, the Robson classification tool has provided a simple, replicable process by which clinicians can examine their own unit practices. Such a process allows the development and implementation of tailored solutions to initiate change. The greatest value of continued use of such a tool will also be the ability to monitor change over time as well as provide the opportunity to make comparison with similar units.

\section{REFERENCES}

Albers, L. (2005). Safety of VBACs in birth centers: Choices and risks. Birth, 32(3), 229-231.

Alfirevic, Z., Devane, D., \& Gyte, G. (2006). Continuous cardiotocography (CTG) as a form of electronic fetal monitoring (EFM) for fetal assessment during labour. Cochrane Database of Systematic Reviews, (3), CD006066. http//:dx.doi.org/10.1002/14651858.CD006066

American College of Obstetricians and Gynecologists. (2010). Vaginal birth after previous cesarean delivery. Washington, DC: Author.

Belizan, J. M., Althabe, F., \& Cafferata, M. L. (2007). Health consequences of the increasing caesarean section rates. Epidemiology, 18(4), 485-486.

Boulvain, M., Stan, C., \& Irion, O. (2005). Membrane sweeping for induction of labour. Cochrane Database of Systematic Reviews, (1), CD000451.

Brennan, D. J., Murphy, M., Robson, M. S., \& O’Herlihy, C. (2011). The singleton, cephalic, nulliparous woman after 36 weeks of gestation: Contribution to overall cesarean delivery rates. Obstetrics and Gynecology, 117(2, Pt. 1), 273-279.

Burgos, J., Melchor, J. C., Pijoan, J. I., Cobos, P., FernandezLlebrez, L., \& Martinez-Astorquiza, T. (2011). A prospective study of the factors associated with the success rate of external cephalic version for breech presentation at term. International Journal of Gynecology and Obstetrics, $112(1), 48-51$.
Cahill, A. G., Stamilio, D. M., Odibo, A. O., Peipert, J. F., Ratcliffe, S. J., Stevens, E. J., . . Macones, G. A. (2006). Is vaginal birth after cesarean (VBAC) or elective repeat cesarean safer in women with a prior vaginal delivery? American Journal of Obstetrics and Gynecology, 195(4), 1143-1147.

Cahill, A. G., Tuuli, M., Odibo, A. O., Stamilio, D. M., \& Macones, G. A. (2010). Vaginal birth after caesarean for women with three or more prior caesareans: Assessing safety and success. BJOG: An International Journal of Obstetrics and Gynaecology, 117(4), 422-427.

Caughey, A. B., Sundaram, V., Kaimal, A. J., Gienger, A., Cheng, Y. W., McDonald, K. M., . . . Bravata, D. M. (2009). Systematic review: Elective induction of labor versus expectant management of pregnancy. Annals of Internal Medicine, 151(4), 252-263.

Costa, M. (2010). Using a caesarean section classification system based on characteristics of the population as a way of monitoring obstetric practice. Reproductive Health, $7(13), 1-8$.

Daviss, B., Johnson, K. C., \& Lalonde, A. B. (2010). Evolving evidence since the term breech trial: Canadian response, European dissent, and potential solutions. Journal of Obstetrics and Gynaecology Canada, 32(3), 217.

Dodd, J., Crowther, C., Huertas, E., Guise, J., \& Horey, D. (2004). Planned elective repeat caesarean section versus planned vaginal birth for women with a previous caesarean birth. Cochrane Database of Systematic Reviews, (4), CD004224. http://dx.doi.org/10.1002/14651858. CD004224.pub2

Fahy, K. (2011). Is breech birth really safe? Treatment validity in the term breech trial. Essentially MIDIRS, 2(10), 17-21.

Fenwick, J., Gamble, J., \& Mawson, J. (2003). Women's experiences of caesarean section and VBAC. A birthrites initiative. International Journal of Nursing, 9(1), 10-17.

Flamm, B. L., Goings., J. R., Liu, Y., \& Wolde-Tsadik, G. (1994). Elective repeat cesarean delivery versus trial of labor: A prospective multicenter study. Obstetrics and Gynecology, 83(6):927-32.

Flamm, B. L., Lim, O., Jones, C., Fallan, D., Newman, L., \& Mantis, J. (1988). Vaginal birth after cesarean section: Results of a multicenter study. Americal Journal of Obstetrics and Gynecology, 158(5), 1079-1084.

Fok, W., Chan, L., Tsui, M., Leung, T., Lau, T., \& Chung, T. (2006). When to induce labor for post-term? A study of induction at 41 weeks versus 42 weeks. European Journal of Obstetrics, Gynecology and Reproductive Biology, 125(2), 206-210.

Glezerman, M. (2006). Five years to the term breech trial: The rise and fall of a randomized controlled trial. American Journal of Obstetrics \& Gynecology, 194(1), 20-25. 
Grootscholten, K., Kok, M., Oei, S. G., Mol, B. W. J., \& Van der Post, J. A. (2008). External cephalic version-related risks: A meta-analysis. Obstetrics and Gynecology, 112(5), 1143-1151.

Gülmezoglu, A., Crowther, C., \& Middleton, P. (2006). Induction of labour for improving birth outcomes for women at or beyond term. Cochrane Database of Systematic Reviews, (4), CD004945. http://dx.doi. org/10.1002/14651858.CD004945.pub2

Hannah, M. E., Hannah, W. J., Hellmann, J., Hewson, S., Milner, R., \& Willan, A. (1992). Induction of labor as compared with serial antenatal monitoring in post-term pregnancy. A randomized controlled trial. The Canadian Multicentre Post-term Pregnancy Trial Group. The New England Journal of Medicine, 326(24), 1587-1592.

Hannah, M. E., Hannah, W. J., Hewson, S. E., Hodnett, E. D., Saigal, S., \& Willan, A. R. (2000). Planned caesarean section versus planned vaginal birth for breech presentation at term: A randomised multicentre trial. Term Breech Trial Collaborative Group. The Lancet, 356(9239), 1375-1383.

Harrington, L. C., Miller, D. A., McClain, C. J., \& Paul, R. H. (1997). Vaginal birth after cesarean in a hospitalbased birth center staffed by certified nurse-midwives. The Journal of Midwifery \& Women's Health, 42(4), 304-307.

Hehir, M., O'Connor, H., Robson, M., Fitzpatrick C., CoulterSmith, S., \& Malone, F. (2011, February). 862: The effect of the term breech trial on vaginal breech delivery 8 years on. Americal Journal of Obstetrics \& Gynecology, 204(1, Suppl.), S334. Poster presented at the Society for Maternal-Fetal Medicine: 2011 31st Annual Meeting, San Francisco, CA.

Howell, S., Khor, S., \& Johnston, T. (2008). Statbite \#9: Determinants of caesarean section in Queensland, 1997-2006. Brisbane, Queensland, Australia: Health Statistics Centre, Queensland Health.

Hutton, E. K., \& Hofmeyr, G. J. (2006). External cephalic version for breech presentation before term. Cochrane Database of Systematic Reviews, (1), CD000084. http:// dx.doi.org/10.1002/14651858.CD000084.pub2

Ingram, J., Domagala, C., \& Yates, S. (2005). The effects of shiatsu on post-term pregnancy. Complementary Therapies in Medicine, 13, 11-15.

Kelly, A., Kavanagh, J., \& Thomas, J. (2005). Breast stimulation for cervical ripening and induction of labour (Review). Cochrane Database of Systematic Reviews, (3) CD003392. http://dx.doi.org/10.1002/14651858 .CD003392.pub2

King, V. J., Pilliod, R., \& Little, A. (2010). Rapid review: Elective induction of labor. Portland, OR: Center for Evidence-based Policy.
Kotaska, A. (2004). Inappropriate use of randomised trials to evaluate complex phenomena: Case study of vaginal breech delivery. British Medical Journal, 329, 1039-1042.

Landon, M. B., Hauth, J. C., Leveno, K. J., Spong, C. Y., Leindecker, S., Varner, M. W., . . G Gabbe, S. G. (2004). Maternal and perinatal outcomes associated with a trial of labor after prior cesarean delivery. The New England Journal of Medicine, 351(25), 2581-2589.

Li, Z., McNally, L., Hilder, L., \& Sullivan, EA. (2011) Australia's mothers and babies 2009. Perinatal statistics series No 25. Cat no. PER 52. Sydney, New South Wales: AIHW National Perinatal Epidemiology and Statistics Unit.

Macones, G. A., Peipert, J., Nelson, D. B., Odibo, A., Stevens, E. J., Stamilio, D. M., . . Ratcliffe, S. J. (2005). Maternal complications with vaginal birth after cesarean delivery: A multicenter study. American Journal of Obstetrics and Gynecology, 193(5), 1656-1662.

Martin, J. A., Hamilton, B. E., Ventura, S. J., Osterman, M. J. K., Kirmeyer, S., Mathews, T. J., \& Wilson, E. (2009). Births: Final data for 2009. National Vital Statistics Reports, 60(1).

McMahon, M. J., Luther, E. R., Bowes, W. A. Jr., \& Olshan, A. F. (1996). Comparison of a trial of labor with an elective second cesarean section. The New England Journal of Medicine, 335(10), 689-95.

Miller, D. A., Diaz, F. G., \& Paul, R. H. (1994) Vaginal birth after cesarean: A 10-year experience. Obstetrics and Gynecology, 84(2), 255-8.

Mozurkewich, E., Chilimigras, J., Koepke, E., Keeton, K., \& King, V. (2009). Indications for induction of labour: A best-evidence review. British Journal of Obstetrics and Gynecology, 116(5), 626-636.

National Collaborating Centre for Women's and Children's Health. (2004). Caesarean section. London, United Kingdom: RCOG Press.

National Institute For Health and Clinical Excellence. (2011) Caesarean section. NICE clinical guideline 132. Manchester, United Kingdom: Author. Retrieved from http://www.nice.org.uk/cg132

New South Wales Department of Health. (2010). Maternity: Towards normal birth In NSW. A woman friendly birth initiative protecting, promoting \& supporting normal birth. Sydney, New South Wales: NSW Health.

Robson, M. (2001). Classification of caesarean sections. Fetal and Maternal Medicine Review, 12(1), 23-39.

Royal College of Midwives, Royal College of Obstetricians and Gynaecologists, \& National Childbirth Trust. (2007) Making normal birth a reality. Consensus statement from the Maternity Care Working Party. Retrieved from 
http://www.rcog.org.uk/files/rcog-corp/uploaded-files/ JointStatmentNormalBirth2007.pdf

Royal College of Obstetricians and Gynaecologists. (2007). Green-top Guideline No. 45: Birth after previous caesarean section. London, United Kingdom: Author.

Rozen, G., Ugoni, A. M., \& Sheehan, P. M. (2011). A new perspective on VBAC: A retrospective cohort study. Women and Birth, 24, 3-9.

Shipp, T. D., Zelop, C. M., Repke, J. T., Cohen, A., Caughey, A. B., \& Lieberman, E. (1999). Intrapartum uterine rupture and dehiscence in patients with prior lower uterine segment vertical and transverse incisions. Obstetrics and Gynecology, 94(5, Pt. 1), 735-40.

Siozos, C., \& Stanley, K. P. (2005). Prolonged pregnancy. Current Obstretics and Gynaecology, 15, 73-79.

Slavin, V., \& Roberts, D. (2010). Emergency Caesarean Section Audit 2010 Gold Coast Hospital. Unpublished manuscript, Queensland Health, Southport.

Smith, C. A., \& Crowther, C. A. (2004). Acupuncture for induction of labour. Cochrane Database of Systematic Reviews, (1), CD002962. http://dx.doi,org/10.1002/14651858. CD002962.pub2

Stamilio, D. M., \& Shanks, A. (2008). Vaginal birth after cesarean (VBAC). Outcomes associated with increasing number of prior VBACs. Women's Health, 4(3), 233-236.

Statewide Maternity and Neonatal Clinical Guidelines Program. (2009). Vaginal birth after caesarean section: Queensland Health.

Sullivan, E. A., Moran, K., \& Chapman, M. (2009). Term breech singletons and caesarean section: A population study, Australia 1991-2005. Australian and New Zealand Journal of Obstetrics and Gynaecology, 49(5), 456-460.
Tahseen, S., \& Griffith, M. (2010). Vaginal birth after two caesarean sections (VBAC-2) - a systematic review with meta-analysis of success rate and adverse outcomes of VBAC-2 versus VBAC-1 and repeat (third) caesarean sections. British Journal of Obstetrics and Gynecology, 117(1), 5-19.

Tan, J. M., Macario, A., Carvalho, B., Druzin, M. L., \& El-Sayed, Y. Y. (2010). Cost-effectiveness of external cephalic version for term breech presentation. BMC Pregnancy and Childbirth, 10, 3. Retrieved from http:// www.biomedcentral.com/1471-2393/10/3

Torloni, M. R., Betran, A. P., Souza, J. P., Widmer, M., Allen, T., Gulmezoglu, M., \& Merialdi, M. (2011). Classifications for cesarean section: A systematic review. PLoS ONE, 6(1), e14566. http://dx.doi.org/10.1371/journal. pone. 0014566

World Health Organization. (1985). Appropriate technology for birth. Lancet, 2(8452), 436-437.

World Health Organization, United Nations Population Fund, United Nations Children's Fund, Averting Maternal Death and Disability. (2009). Monitoring emergency obstetric care: A handbook. Geneva, Switzerland: Author.

Correspondence regarding this article should be directed to Valerie Slavin, BSc Mid. RM, Gold Coast Hospital, Queensland, Australia. E-mail: valerie.slavin@griffithuni.edu.au

Valerie Slavin, BSc Mid. RM, Clinical Midwife, Gold Coast Hospital, Queensland, Australia.

Jennifer Fenwick, PhD, RM, Professor of Midwifery, Griffith University \& Gold Coast Hospital, Queensland, Australia. 